\title{
Artesanato: entre Patrimônio e Mercado
}

\author{
Artesanía: entre el patrimonio y el Mercado
}

\section{Crafts: between Heritage and Market}

\begin{abstract}
Miriel Bilhalva Herrmann'
Resumo

O presente trabalho busca estabelecer uma analise em relação a questão do artesanato, de como sofre modificações e interferências. Na qual no seu inicio tinha apenas valor utilitário, pois era produzido para suprir necessidades humanas. E com a revolução industrial foi relegada a marginalização, assim perdeu seu espaço para as máquinas. Mas logo com o intuito de criar identidades nacionais, começam as discussões em relação ao patrimônio. Dessa forma as concepções e ampliação sobre o seu conceito, propiciou grande valorização das diversidades culturais, assim como as técnicas artesanais. E a partir disso o artesanato passa a ser percebido como patrimônio, sendo visto e utilizado pelo turismo como fator de desenvolvimento econômico, dessa forma ocasionando um dilema entre estas técnicas artesanais de como se manter tradicionais, referência para a cultura e a identidade cultural. Ao mesmo tempo atender as necessidades do consumidor que se apresenta como turista, pois necessitam se adaptar para continuar sobrevivendo as mudanças do mercado.
\end{abstract}

Palavras-Chave: Artesanato. Mercado. Patrimônio.

\section{Resumen}

Este documento tiene por objeto establecer un análisis con respecto a la cuestión de la artesanía, ya que sufre cambios y las interferencias. En el que en sus inicios era único valor utilitario, que fue producido para satisfacer las necesidades humanas. Y con la revolución industrial fue relegado a la marginación, por lo tanto perdido su espacio para las máquinas. Pero pronto el fin de crear identidades nacionales comienzan las discusiones en relación con la equidad. Así, los conceptos y ampliando el concepto, condujo a un gran aprecio de la diversidad cultural, así como las técnicas tradicionales. Y desde que la nave se percibe como una herencia, ser visto y utilizado por el turismo como factor de desarrollo económico, lo que provoca un dilema entre estas técnicas tradicionales de cómo mantener la tradicional referencia a la cultura y la identidad cultural. Al mismo tiempo, satisfacer las necesidades de los consumidores se presenta como un turista, porque tienen que adaptarse para seguir sobreviviendo los cambios del mercado.

Palabras claves: Artesania. Mercado. Patrimonio

\begin{abstract}
This paper seeks to establish an analysis regarding the issue of handicrafts, as he suffers changes and interferences. In which at its inception was only utilitarian value, it was produced to meet human needs. And with the industrial revolution was relegated to marginalization, thus lost its space for the machines. But soon in order to create national identities begin discussions in relation to equity. Thus the concepts and expanding on the concept, led to great appreciation of cultural diversity, as well as traditional techniques. And from that the craft is perceived as a heritage, being seen and used by tourism as an economic development factor, thereby causing a dilemma between these traditional techniques of how to keep traditional reference to culture and cultural
\end{abstract}

\footnotetext{
${ }^{1}$ Universidade Federal do Pampa - Unipampa; Campus Jaguarão, Rio Grande do Sul, Brasil. miribilha@yahoo.com.br
} 
identity. At the same time meet the needs of the consumer is presented as a tourist, because they need to adapt to continue surviving the market changes.

Keywords: Craft. Market. Heritage.

\section{Introdução}

O passado sempre foi relevante a todos, o lembrar e jamais esquecer sempre esteve acompanhando a história da humanidade. Entre os séculos XIX e XX o patrimônio, os bens culturais construídos pelo homem em sociedade começam a ser pensados e vistos como monumentos históricos. Sendo que, a França em 1837 foi pioneira em criar uma comissão de monumento histórico, constituindo um modelo de classificação em que Antiguidades representariam as igrejas e construções da idade media. Como também, desenvolveu em 1913 a primeira lei de Monumento histórico, até então registradas (BRANCO, 2009).

A discussão sobre o patrimônio se concretizou no século XIX no período pós-guerra quando a "legislação francesa passa a ser referência para o mundo" (RIBEIRO, 2005, p.44). Essa preocupação com a questão do patrimônio se da a partir da preocupação dos Estados em forjar uma identidade nacional, e isso se daria através de conjuntos e monumentos arquitetônicos já existentes. Então até 1960 o patrimônio ainda estava vinculado a prédios edificados, como grandes construções religiosas e públicas que representavam uma riqueza arquitetônica.

A partir disso no Brasil, o discurso sobre a classificação de bens culturais considerados patrimônio só se modificou nos anos 80. Essas mudanças, de acordo com Pelegrini (2007), ocorreram devido ao fervor das mobilizações e movimentos sociais, principalmente vinculados a questões de etnia e gênero, buscando o reconhecimento da diferença e diversidade cultural. Então conforme o artigo 216 da Constituição de 1988 a noção de patrimônio é ampliada:

\footnotetext{
Constituem patrimônio cultural brasileiro os bens de natureza material e imaterial, tomados individualmente ou em conjunto, portadores de referência à identidade, à ação, à memória dos diferentes grupos formadores da sociedade brasileira, nos quais se incluem: as formas de expressão; os modos de criar, fazer e viver; as criações científicas, artísticas e tecnológicas; as obras, objetos, documentos, edificações e demais espaços destinados às manifestações artístico-culturais; os conjuntos urbanos e sítios de valor histórico, paisagístico, artístico, arqueológico, paleontológico, ecológico e científico (CONSTITUIÇÃO, 1988).
}

Logo, patrimônio cultural é tudo aquilo que tem sentido e importância para a coletividade, seja ele material ou imaterial. A autora Choay (2006) percebe o patrimônio cultural como determinada coisa que se encontra preso a estruturas familiares, econômicas e 
jurídicas de uma sociedade, situadas no tempo e no espaço. Sendo assim, algo que somente adquire valor patrimonial se estiver vinculado a algum domínio social, pois através deste o bem adquire sentido.

O conceito de patrimônio cultural vem se modificando ao longo do tempo, dessa maneira se tornando mais amplo. Deste modo não considerando somente os bens materiais, monumentos arquitetônicos como importantes a serem protegidos, essa concepção reduzia a ideia de patrimônio, que estava relacionada a grande arquitetura, belas artes, ou seja a cultura erudita, que consiste em um mundo diferente e tangível a poucas pessoas detentora de um grau de escolaridade superior, possuidoras de mecanismos de decodificação dos códigos (BOURDIEU; MARTIN, 1976).

O patrimônio cultural contribui para conservação da identidade cultural de grupos sociais e também para a sua construção, dessa forma é o conjunto de valores que é comum entre um grupo, fazendo com que se localizem e sejam localizados dentro da sociedade. Através dele podemos entender melhor o momento histórico, social e econômico de uma sociedade. Nesse sentido os bens culturais adquirem duplo papel na qual proporcionam conhecimento e causam sensações, desde estranhamento e contemplação, podendo se tornar plastificado, facilitando o seu consumo (CHOAY, 2006). Pois, para Jacques (2008), cultura acaba por cumprir a função de uma ferramenta de ação voltada para o crescimento econômico local e nacional.

Assim sendo como na Convenção para Salvaguarda do Patrimônio Cultural Imaterial de 2003 pela UNESCO "reconhece que as comunidades, os grupos e indivíduos desempenham um importante papel na produção, salvaguarda, manutenção e recriação do patrimônio cultural imaterial, assim contribuindo para enriquecer a diversidade cultural" (JACQUES, 2008).

\section{Discussão}

Todos estes desdobramentos sobre a ampliação do conceito de patrimônio se dá através de demandas políticas, econômicas e simbólicas que se configuraram no mundo com o advento do mundo moderno e globalizado. Mostrando que não há somente uma cultura nacional, mas diversas. Dessa maneira, voltando o olhar para o âmbito local. Contudo, possibilitou o reconhecimento da importância do patrimônio imaterial para a diversidade cultural e garantia de desenvolvimento sustentável (ALVES, 2010).

Dessa forma era preciso criar referências para uma sociedade que se via em uma constante e acelerada mutação. Tendo a necessidade de proteger e salvaguardar monumentos, 
objetos, assim como as tradições passadas de forma oral, que é quando um conhecimento é transmitido por meio da oralidade de uma geração para outra (VANSINA, 1985). Assim como a técnica artesanal que é passada por meio da tradição oral.

E é neste contexto que o artesanato, é reconhecido como patrimônio imaterial, sendo parte importante da cultura tradicional e popular, contribuindo para a diversidade cultural. Inicialmente o artesanato era produzido para suprir as necessidades do cotidiano, eram feitos vestimentas, móveis, utensílios e vários outros artefatos. Os artesãos formavam grupos numerosos, na qual compartilhavam seus conhecimentos no meio urbano, pois no meio rural a produção artesanal era mais voltada para o trabalho rural. Tudo era produzido de forma manual (COLVERO; MATEOS, 2010).

De acordo com Keller (2014), o artesanato não pode se restringir somente a um simples serviço manual. Apresenta em si a aptidão de esquematizar e de inventar artefatos baseados em elementos da cultura, assim como a propriedade do saber/fazer, da técnica. Podemos localizar várias técnicas artesanais que contribuem para a diversidade cultural, são tantas que é impossível determinar o que é artesanato, já que possui muitas particularidades, na qual o que é produzido pode ser "utilitário, estético, artístico, criativo, relacionado à cultura, decorativos, práticas tradicionais e de valor simbólico do ponto de vista religioso e social” (Conferência das nações unidas sobre comércio e desenvolvimento, 2010).

Entretanto, na sociedade moderna, com a Revolução Industrial no século XVIII o oficio artesanal passa a ter caráter de incerteza. Já que houve diversas consequências, com o aumento do crescimento urbano e a implantação de novas tecnologias. Uma vez que, o trabalho manual passa a ser mecanizado. Então, para Palangana e Inumar (2001) ocorrem também alterações na configuração da organização e do método, pois o artesão que anteriormente detinha todo o processo desde a criação, planejamento, execução e comercio. Atualmente conforme afirma Sennett (2009) no mundo industrializado, executa tarefas específicas e individualizadas, segue uma rotina de horários, baseada em uma meta de produção que visa o lucro e não a subsistência.

Nesta nova conjuntura que se formou o trabalho manual não teve condições de competir com a produção industrializada. Para Canclini (1995), os trabalhos artesanais obedecem a outra forma de fabricação, que no meio urbano acabaram sendo supridas pelas indústrias, onde a disputa é desfavorável, levando os artesãos à prática de serviços marginais. Uma vez que o artesanato é uma atividade, que prevê mais tempo e dedicação para a sua produção, não existe a possibilidade de este ser produzido em grande escala, sua fabricação é de forma manual, não se obtém perfeição. Entretanto o artesanato é muito mais que simples 
reprodução e processo de produção. Seu significado só é acertado relacionando-o com o contexto em que está inserido, vinculando-o com as práticas sociais que envolvem todo processo de criação e de subjetivação (CANCLINI, 1995).

E esse artesanato que antes tinha um caráter utilitário, era o único meio de suprir as necessidades do ser humano. Com o passar do tempo e as mudanças que a sociedade sofreu, ele ficou no esquecimento em detrimentos dos produtos industrializados. Sua transmissão por muito tempo foi ligada a tarefa feminina, por isso como afirma Eggert (2011) muitas vezes a atividade artesanal não é percebida como trabalho, pelo fato de tradicionalmente ser realizada no campo doméstico e familiar, também por servirem para complemento de renda.

A partir do século XX, a prática artesanal torna-se mecanismo de ação voltado para os movimentos em prol da identidade, memória, tradição e do reconhecimento do passado no presente. Com isso, o rústico, o feito a mão, o imperfeito passa a ser valorizado (CANCLINI, 1995). Pois é percebido como uma forma de hierarquização social do sujeito, provocando um sentimento ilusório de diferenciação do "eu" para com o "outro".

Ou seja, o produto industrial, em série, padronizado, com preços acessíveis a todas as camadas econômicas, é um objeto em sua maioria plastificado, que segue uma tendência de modismo, que vende em certo período, mas logo deve sofrer modificações para atender a demanda do mercado. Nesse sentido o artesanato com toda essa valorização simbólica, esta se direcionando para esta mesma realidade.

Neste caso, o artesão acaba por ter que adaptar a forma de criação de seus artefatos, para da mesma forma que o industrial atender o desejo dos consumidores, pois necessita vender o que produz para sobreviver. A atividade artesanal envolve muitos significados. No entanto o artesão que possui o controle do processo de produção e criação do artesanato, na qual este cria a partir do seu imaginário. Atualmente necessita a tender a uma demanda mercadológica, modificando o seu modo tradicional de fazer. Sendo assim deixo aqui algumas indagações: Se um artesanato se modifica muito ele ainda é artesanato? E se não se modificar ele sobrevive às mudanças? Não há mais a sua fonte de matéria prima para a execução? Deixa de existir ou se adapta?

Todas estas questões deixam a questão do artesanato conturbada e confusa. Pois para ser valorizado precisa ser tradicional, ter valor cultural e ser significativo para certo grupo ou comunidade. Mas ao mesmo tempo precisa se adaptar para poder resistir e atender ao anseio do mercado turístico. $\mathrm{O}$ artesanato com valor patrimonial passa a ser fator de desenvolvimento local, utilizado como elemento de crescimento para o setor do turismo. 
Patrimonializados, os bens servem para o consumo e como fonte para importância e visibilidade local.

A questão a ser pensada é mediante esta ação, quais serão os sentidos atribuídos a cultura local e aos bens culturais. E, principalmente, como estes serão reconhecidos, consumidos e percebidos pelos consumidores e produtores dos mesmos. Assim, quaisquer que sejam os sentidos atribuídos, a patrimonialização é vetor de desenvolvimento, pois, ao se levar em conta a comercialização de mercadorias, promove-se o desenvolvimento econômico. Nesse sentido aponta Dominique Poulot (2008):

A nação torna-se a encarnação por excelência da patrimonialidade, absorvendo, por assim dizer, no seu princípio, toda a recepção dos objetos culturais do passado, apropriação se dá na forma de uma comunidade imaginária, e a proteção do patrimônio é geralmente acompanhada de uma crença em um progresso (POULOT, 2008, p.30).

Uma vez que, há o deslocamento de uma região para outra, abertas para o turista consumir algo com uma carga simbólica, desconhecida para esse sujeito. E este sujeito vai consumir o objeto na qual supostamente o conhece, passa a conhecer sua história. Assim levando este artefato para o seu contexto, apenas para decoração, lhe conferindo status e distinção social.

Este produto artesanal patrimonializado dentro do seu contexto local, ele possui diversos valores que envolve as imaginações, afetos, crenças, as práticas. E para o turista destituído de um vinculo pessoal e comunitário, o artesanato é apenas um bem cultural a ser consumido (MENEZES, 2012). Nesse sentido argumenta Tilley (2006):

O turismo é um processo que resulta na subordinação dos moradores dependentes na reconstituição mítica de tradições arrancadas pela globalização. O turista vai de férias para buscar consolo, para encontrar fontes de cultural património e identidade que a modernidade tem destruído, um outro mundo ( TILLEY,2006, p.16).

Em cidades que são patrimônio histórico ou possuem artefatos patrimonializados, o turismo é intenso, e para atender o processo turístico, necessita focar na representação do passado. Assim ocorre uma representação, imitação, na qual o conceito do presente substitui o do passado, sem distinguir entre verdadeiro e falso. E o artesanato ou bem cultural que anteriormente tinha valor simbólico e fazia sentido somente para a sua comunidade, sem importância fora desse núcleo, sem poder comercial e lucrativo. Sofreu interferências por gestores públicos e privados, visando transformar o bem cultural em produto que pode ser consumido e comercializado (SILVA, 2011). 
O turismo passa a ser elemento de transformação da sociedade e suas manifestações culturais. De acordo com essa situação temos Poulot (2008) que expõe:

Hoje nas sociedades de consumo e de cultura de massa, o uso do patrimônio, sua interpretação, e mesmo atualmente a sua simulação por dispositivos virtuais variados agem como o instrumento, muitas vezes decisivo, de um desenvolvimento local ou nacional, por causa da importância do turismo e das práticas comerciais do saber e do lazer (POULOT, 2008, p.33).

Percebemos que tanto o turismo como o patrimônio histórico ou cultural são constituições sintéticas do presente. Já que são conceitos produzidos pelo homem, que cria e transforma seu ambiente de acordo com a sua necessidade social, cultural ou econômica. Então, o artesanato como bem patrimonial é reinventado, transformado de maneira a ser utilizado como fator de desenvolvimento econômico. E para isso é necessário que o patrimônio ateste identidade e afirme valores, seja representante de uma tradição histórica seja ela totalmente verdadeira ou não (POULOT, 2008).

Para tanto Jacques (2008) narra que há a necessidade de se diferenciar de outras culturas ou aspectos culturais de outras regiões, para que aguce o interesse do turista em conhecer. Pois estes vão ao encontro de algo desconhecido, por isso vão à busca desse patrimônio que represente outros grupos outras identidades.

Pois, o Patrimônio não constitui apenas a herança cultural, expressões culturais "extintas", artefatos antigos, arquitetura colonial, mas também os bens culturais perceptíveis e imperceptíveis assim como, artesanatos, línguas, conhecimentos, que são adequados por meio da indústria cultural (CANCLINI, 1994).

Assim movimentando a cadeia do Turismo e do Patrimônio. Dessa forma os bens patrimoniais passam a ser valorizados, no intuito de fomentar o consumo e o lucro, surgindo assim uma "indústria patrimonial”. Nota-se que o patrimônio imaterial, vinculado a bens com grande carga simbólica e valor de memória, como as técnicas artesanais são utilizados pelo mercado cultural, sendo percebidos como um produto passível de gerar lucro. E assim destituído de seu valor primeiro para agora se transformar em produto a ser consumido apenas. Logo Veloso (2006) aponta:

É preciso, portanto, não espetacularizar ou coisificar o patrimônio, seja material ou imaterial, e um dos procedimentos indispensáveis é não perder de vista o sentido que determinada manifestação cultural tem para o grupo que a produz (VELOSO, 2006).

\section{Conclusão}


Por fim, podemos perceber que a ampliação da concepção do que vem a ser patrimônio, possibilitou que diversas expressões culturais fossem valorizadas, assim como o artesanato. Na qual antes de ser considerado patrimônio, era tido como trabalho marginal. E ainda hoje as diferentes naturezas de produção societária de artesanato no mundo atual que ainda se conservaram, configuram-se tanto como formas de permanência social quanto de resistência cultural.

Mas a partir do momento que é visto como bem patrimonial e também como forma de afirmação identitária e detentor de valor para as memórias sociais. Este passa a ser valorizado e reconhecido, mas não apenas pelo seu aspecto relacionado à identidade, memória e o valor simbólico que o envolve.

Porém este é valorizado e utilizado como vetor de desenvolvimento econômico local. Leite (2003) observa que "o auto dilema do artesanato, cujo debate permanece aberto, é não constituir meramente em produtos, mas em processos que se inserem reflexivamente no contexto de sua produção e se refletem nos modos de vida de quem os produz" (p.41).

Então não se pode perceber o artesanato somente como um produto a ser consumido. Mas deve ser ponderado no contexto em que se insere, pois envolve diferentes valores como afetivos, de familiaridade, de usos e outros, que vão além do simples produto objetificado. É necessário pensar não apenas no produto que é realizado, mas no seu produtor e tudo que envolve essa produção, que é muito mais subjetivo do que uma produção mecanizada.

Portanto, o artesanato somente pensado como tradição, sem se modificar ou se transformar, não sobrevive às mudanças aceleradas da modernidade. Este necessita se adaptar para atender a demanda do consumidor. Já que, sem ter quem o adquira esse artefato não permanece e consequentemente se extinguirá. Então o artesão necessita ter estratégias mercadológicas, mas de maneira que o artefato produzido não perca seus aspectos culturais, que é o que o torna admirável e simbólico. Mas acredito que não é tarefa fácil dosar as duas dimensões, a de mercado e a simbólica.

\section{Referências}

ALVES, E.P. Diversidade Cultural, Patrimônio Cultural Material e Cultura Popular: a Unesco e a construção de um universalismo global. Soc. Estado. v.25. n.3. p.539-560. Dezembro, 2010.

BRANCO, P. M. C. Patrimônio Histórico e Turismo: Uma Construção Social. Veículo de Publicação não especificado. 2009.

BRASIL. Constituição da República Federativa do Brasil, de 05 de outubro de1988. 
CANCLINI, Nestor Garcia. As Culturas populares no Capitalismo. São Paulo, Brasiliense, 1995.

CANCLINI, Nestor. O patrimônio cultural e a construção do imaginário nacional. In: Revista do Instituto do Patrimônio Histórico e Artístico Nacional. Brasília: IPHAN/ MINC, n. 23, 1994.

CHOAY, Françoise. A Alegoria do Patrimônio. 3 ed. São Paulo: Unesp, 2006.

CONFERÊNCIA DAS NAÇÕES UNIDAS PARA COMÉRCIO E DESENVOLVIMENTO. Relatório de economia criativa. Nações Unidas, 2010.

COVELO, Natalia; MATEOS, Cristina. Mercado De Artesanías En El Uruguay. Monografia. Faculdad de la Republica, 2010.

EGGERT, Edla. Processos educativos no fazer artesanal de mulheres do Rio Grande do Sul, $1^{\circ}$ ed., Santa Cruz do Sul: EDUNISC, 2011.

JACQUES, Paola B. Patrimônio cultural urbano: espetáculo contemporâneo? Revista de Urbanismo e Arquitetura, América do Norte, 6, dez. 2008. Disponível em: http://www.portalseer.ufba.br/index.php/rua/article/view/3229/2347. Acesso em: 06 ago. 2016.

KELLER, Paulo. O artesão e a economia do artesanato na sociedade contemporânea. Maranhã, Revista de ciências sociais, $n^{\circ} 41,2014$.

LEITE, Rogério Proença. Modos de Vida e Produção Artesanal: entre preservar e consumir. IN: Olhares Intinerantes reflexões sobre o artesanato e consumo da tradição. São Paulo: Cadernos Artesol 1, Central Artesol, 2003.

MENESES, Ulpiano Toledo Bezerra. O campo do Patrimônio Cultural: Uma Revisão de Premissas. In: I FÓRUM NACIONAL DO PATRIMÔNIO CULTURAL, 2009, Ouro Preto. Brasília: Iphan, 2012.

MIRANDA, Marcos Paulo de Souza. Tutela do Patrimônio brasileiro: doutrina, jurisprudência, legislação, Belo Horizonte: Del Rey, 2006.

PALANGANA, Isilda Campaner; INUMAR, Lucélia Yumi. A individualidade no âmbito da sociedade industrial. Psicologia em Estudo, Maringá, v. 6, n. 2, p. 21-28, jul./dez. 2001.

PELEGRINI, Sandra C. A. O patrimônio cultural e a materialização das memórias individuais e coletivas. Patrimônio e Memória, UNESP/FCLAs/CEDAP, v.3, n.1, p. 95-109, 2007.

POULOT, D. 2008. Um Ecossistema do Patrimônio. In: CARVALHO, C. S. de; GRANATO, M; BEZERRA, R. Z; BENCHETRIT, S. F. (orgs.). Um Olhar Contemporâneo sobre a Preservação do Patrimônio Cultural Material. Rio de Janeiro: Museu Histórico Nacional, p. 26-43. 

e-ISSN 2016/Atual: 2525-7870 | e-ISSN 2015/2016: 2447-018X

Reproduzido de BOURDIEU, P. e SAINT-MARTIN, M. Goftts de classe et styles de vie. (Excerto do artigo "Anatomie du goftt".) Actes de Ia Recherche en Sciences Sociales, $\mathrm{n}^{\circ} 5$, out. 1976, p. 18-43. Traduzido por Paula Montero.

BRASÍLIA: memória, cidadania e gestão do patrimônio cultural. Front Cover. Sandra Bernardes Ribeiro. Annablume, 2005 - Brasília (Brazil) - 205 p.

SANDOVAL, Carolina da Graça, ARRUDA, Jéssica Silva, SANTOS, Natália Cabral. Ouro Preto Impactos da atividade turística em uma cidade tombada, revista Itinerário v.2, 2009.

SENNETT, Richard. A corrosão do caráter: as consequências pessoais do trabalho no novo capitalismo. 14 ed. Rio de Janeiro, Record, 2009.

SILVA, Vanessa Regina Freitas da. Patrimônio, Memória e Mercadoria: uma reconstrução arquitetônica em Ouro Preto, Minas Gerais. Pelotas: 2011. Dissertação (Mestrado em Memória Social e Patrimônio Cultural).

TILLEY, C. 2006. Identity, Place, Landscape and Heritage. Journal of Material Culture, (11): $1 / 2,7-32$.

UNESCO (2003) Convenção Para Salvaguarda do Patrimônio Cultural Imaterial, Paris.

VANSINA, Jan: Oral tradition as history. Wisconsin, The University of Wisconsin Press, 1985, p. 27. 